University of Nebraska - Lincoln

DigitalCommons@University of Nebraska - Lincoln

1990

\title{
Spatial Memory in Seed-Caching Corvids
}

\author{
Alan Kamil \\ University of Nebraska - Lincoln, akamil1@unl.edu \\ Russell P. Balda \\ Northern Arizona University, Russell.Balda@nau.edu
}

Follow this and additional works at: https://digitalcommons.unl.edu/bioscibehavior

Part of the Behavior and Ethology Commons

Kamil, Alan and Balda, Russell P., "Spatial Memory in Seed-Caching Corvids" (1990). Papers in Behavior and Biological Sciences. 60.

https://digitalcommons.unl.edu/bioscibehavior/60

This Article is brought to you for free and open access by the Papers in the Biological Sciences at DigitalCommons@University of Nebraska - Lincoln. It has been accepted for inclusion in Papers in Behavior and Biological Sciences by an authorized administrator of DigitalCommons@University of Nebraska - Lincoln. 


\title{
Spatial Memory in Seed-Caching Corvids
}

\author{
Alan C. Kamil \\ University of Massachusetts-Amherst \\ Russell P. Balda \\ Northern Arizona University
}

\section{Introduction}

Traditionally, the psychological study of animal learning and memory has been conducted in laboratory settings with little reference to the natural history, ecology, or evolution of the species being studied (Kamil, 1988). The emphasis has been on identifying and understanding processes that are general across species and paradigms. There seemed to be an (often unstated) assumption that investigating cognitive processes in natural settings was a poor strategy because of the danger of concentrating on "special" abilities (such as imprinting), limited to specific biological settings. The results of research based in specific ecological questions, from this point of view, would be of little general interest, especially to those primarily concerned with generalizing to human cognitive processing.

In a way, psychologists were encouraged in this approach by the attitude of biologists toward learning and memory. Biologists emphasized genetic contributions to behavior, deemphasizing the general role of learning. Although ethologists were interested in certain forms of learning, particularly imprinting and song learning, they tended to view the types of learning typically studied by psychologists as unimportant.

In the last 20-25 years, however, a variety of phenomena have undermined the assumptions of both psychologists and biologists. In psychology, phenomena such as species-specific defensive reactions (Bolles, 
1970), autoshaping (Jenkins \& Moore, 1973; Kamil \& Mauldin, 1987), and taste-aversion learning (Garcia \& Koelling, 1966) have shown that the biology of animals can and does affect the outcome of research using the traditional, arbitrary responses studied in psychological experiments on learning and memory. In biology, phenomena such as optimal foraging (Stephens \& Krebs, 1986) and the development of social behavior (Cheney, Seyfarth, \& Smuts, 1986) have demonstrated that learning and memory play crucial roles for animals in their natural habitat (see Shettleworth, 1984, for discussion of learning and behavioral ecology). These developments establish that the study of learning and memory must involve both psychological and ecological approaches.

If this conclusion is correct, then psychologists need to broaden the way in which they select problems for study. In biology, as in psychology, one approach is to study general processes. Following this approach, one selects the species for study on the basis of convenience or because it has some desirable characteristic, such as short generation time (as in fruit flies for geneticists). This, of course, is the approach that has dominated animal psychology. But there is an alternative approach in biology, one that looks at organisms and their interactions with their environments. In this approach, one selects species and problems for study based upon natural history and ecology.

Our purpose in this article is to review the results of our studies of the mechanisms underlying cache recovery by members of the crow, jay, and nutcracker family. In this research program, we have combined psychological and ecological approaches to the study of memory, and the results demonstrate the utility of this interdisciplinary strategy. Unlike most psychological research on learning and memory, this research program originated in the study of how a particular species solves a particular ecological problem. It serves as an example of how natural history and ecology can provide the starting point for a research program that produces interesting and surprising data of general importance. We begin by outlining the ecological problem.

\section{The Ecological Problem}

Many animals must cope with cyclic resource availability. The abundance of food may vary on a daily basis or even on a yearly basis. For example, many nuts and seeds are produced only during a relatively short period of time, usually in the fall in temperate zones. Foragers often contend with this variation in resource availability by harvesting and storing food during periods of abundance, using the cached food during periods 
of food scarcity (Vander Wall \& Smith, 1987). This specialization is shown by many corvids who cache acorns, beech nuts, hazel nuts, pine seeds, etc. Many caching animals create large, centralized food stores, such as the middens of squirrels or the honeycombs of bees. Corvids, however, disperse their cached food in many distinct locations, often buried in the ground (Balda, Bunch, Kamil, Sherry, \& Tomback, 1987; Turcek \& Kelso, 1968).

A particularly spectacular example of distributed caching is provided by the two members of the Nucifraga genus, the Eurasian (N. cartyocatactes) and the Clark's (N. columbiana) nutcrackers. Our research has focused on the North American species, Clark's nutcracker, which is named for its discoverer. Captain William Clark, who first encountered this bird on the historic Lewis and Clark expedition. The name nutcracker comes from the birds' unusual ability to open the thick hulls of seeds using only the bill. Whereas most birds must hold a seed in the foot and peck at it, nutcrackers commonly remove the shell from seeds with a simple, forceful closing of the bill.

The nutcracker is a bird of the high mountains of western North America, where it is a year-round inhabitant of the coniferous forests. Winters in this habitat are cold, with deep snow, short days, and high winds. This environment is not a very hospitable place to live and breed. Nutcrackers counter these harsh conditions by accumulating a store of food for use during the winter and early spring, when food would otherwise be unavailable.

During August and early September, nutcrackers begin to harvest seeds from the cones of alpine species of pine trees which have just begun to ripen. Green cones are shredded to bits with the long, sharp, sturdy bill, and the extracted seeds are placed in the sublingual pouch located in the floor of the mouth, which can hold up to 95 seeds (Bock, Balda, \& Vander Wall, 1973). These seeds may be transported up to $22 \mathrm{~km}$ from the harvest site and then buried in thousands of discrete subterranean caches. The seeds in these caches are buried 2-3 cm deep in the soil. The birds usually leave no physical signs of digging on the surface so that these caches are difficult, if not impossible, to detect visually. A single bird can cache up to 33,000 seeds in about 6,600 separate locations during a fall when a bumper cone crop is produced (Vander Wall \& Balda, 1977).

These seeds form the bulk of the diet during the winter and the spring breeding season, when other foods are scarce. A single bird needs about 9,900 seeds to survive the winter. About 5 seeds are buried per cache, thus a nutcracker must have access to about 1,980 caches per winter for its own survival. In addition, however, nutcrackers are one of the earliest-breeding birds in North America. Breeding occurs from February to 
April when snow covers the ground and nighttime temperatures are below freezing. Young nutcrackers are fed pine seeds removed from caches created during the previous autumn by both parents.

The winter survival and breeding success of the Clark's nutcracker depends upon cached pine seeds. In years when the pine cone crop is poor, the birds usually forego breeding. They leave their breeding area in the mountains, descending to lower altitudes. In such years they do not breed and many of the birds die. The food stored in caches is crucial for these birds, as is the ability to successfully relocate the stored pine seeds (Mewaldt, 1956).

The problem of later utilization of stored food is, of course, an important one for all caching animals. Some animals, such as honeybees or midden-creating squirrels, place all of their stored food in a single larder. For such central-place storers, the major problem is defending the larder against competitors. But animals such as nutcrackers that disperse their food stores face a very different set of problems. First, the caches must be hidden, providing no obvious cues as to their location, so that the stored food is less vulnerable to theft by other animals. Second, the hidden, cached food must be relocated by the original cacher. Many techniques could be used, including direct cues such as odor, systematic cache placement, site preferences, and spatial memory. The first step in any research program investigating cache recovery is to determine how caches are found.

\section{How Do Nutcrackers Find Their Seeds?}

Field studies of nutcrackers in natural situations clearly show that they can accurately find specific locations of hidden seed caches up to 11 months after making them. For example, Tomback (1980) tabulated the percentage of probe holes that had empty seed hulls next to them, which provides a conservative estimate of success rates (because the birds occasionally fly off with recovered seeds, although they usually husk them at the site). She found that this percentage ranged between 60 and $80 \%$. Vander Wall and Hutchins (1983) observed nutcrackers probing in the ground in the spring, at least 8-9 months after caching, and directly observed hit rates of $44 \%$. Conrads and Balda (1979) have seen nutcrackers probe with $84 \%$ accuracy after the birds had made thousands of caches.

These observational data make it clear that cache recovery is a phenomenon worthy of further investigation. Whatever technique the nutcrackers are using, it is highly accurate. Imagine that you are about to dig for a small cache of pine seeds, perhaps $5 \mathrm{~cm}$ in diameter, and all you 
have to dig with is a bill 1-2 cm wide. Even if there were several caches per square meter, hit rates as high as $10 \%$ would be impossible to obtain by chance.

Several mechanisms could be employed, but each appears to have a significant problem associated with it:

1. Cues emanating directly from the seeds, such as odor, which direct digging behavior. However, such cues would also be available to competitors and significant amounts of stored food might be lost.

2. Site preferences which direct digging during both caching and recovery. However, such preferences would have to be extremely specific, allowing accuracy on a very fine-grain level.

3. Fixed movement paths which are followed during caching and recovery. Again, these would have to be extremely fine-grained.

4. Memory for specific cache sites. This seems unlikely because of the large number of sites to be remembered and the relatively long duration of memory implied by natural history.

Although the observational field data brought this problem to our attention, it is apparent that controlled experimental testing was necessary to determine the mechanism underlying accurate cache recovery by nutcrackers. The first such study (Balda, 1980) found that a Eurasian nutcracker would cache and accurately recover seeds in a dirt-floor aviary. Most importantly, Balda conducted a control experiment. After the bird had cached, Balda removed the seeds from the caches and reraked the soil. During recovery sessions, the bird returned to the locations where seeds had been buried, demonstrating that cues given off by the cached pine seeds were not necessary for accurate recovery.

Vander Wall (1982) extended these findings with a study of Clark's nutcrackers in an outdoor aviary. He found that when two nutcrackers cached in the same area at different times and then separately recovered caches, each bird only recovered its own caches. This also indicates that direct cues from cached seeds are not responsible for cache recovery. If direct cues were being used, then each bird should have found at least some of the seeds cached by the other bird. In addition, when Vander Wall moved the landmarks in part of the aviary, leaving the cached seeds in place, the birds' digging behavior was displaced away from the seed. The displacement indicated that the birds were using the landmarks to relocate caches.

Kamil and Balda (1985) carried out an additional control. They used a room with 180 holes in the floor. Each hole could either be filled with a tight-fitting, sand-filled cup or be capped with a wooden plug. During caching sessions, most of the holes were plugged, forcing the birds to 
cache in a widely dispersed, randomly chosen set of holes. During recovery sessions, all holes were open. Even under these conditions, when the experimenters, rather than the birds, chose the cache sites, the birds were able to recover caches accurately. If site preferences were responsible for accurate cache recovery, performance should have deteriorated when the birds were forced to cache in sites chosen by the experimenters. In addition, there was no consistent relationship between cache order and recovery order (see below), eliminating systematic movement patterns as necessary for accurate cache recovery.

These experimental results clearly indicate that the most reasonable explanation for the accurate cache recovery of nutcrackers is spatial memory for cache sites. This, in turn, raises many questions. In the next section, we discuss what is known about the characteristics of the spatial memory system of nutcrackers.

\section{The Characteristics of Cache Site Memory in Nutcrackers}

\section{A. The Role of Preferences During Cache Recovery}

As described above, only a limited number of holes in the floor are available to the nutcrackers for caching during most of our experiments. In one such experiment (Kamil \& Balda, 1985) we directly compared the cache recovery accuracy of four nutcrackers after they were given a large number of holes to select from (90) with accuracy after they were forced to select caches from a very restricted number of holes (8). All four birds recovered their caches at above chance levels during both conditions of this experiment, and the overall level of accuracy was not significantly different between conditions.

One bird in this experiment, however, demonstrated much higher levels of accuracy under the 90-hole condition. This bird had a history of poor performance in other experiments when few holes were present for caching, but performed extremely well after 90 holes were available. It is possible that for this individual, site preferences were important and could only be utilized during the 90-hole condition.

In another experiment (Balda \& Kamil, 1989) we compared the cache recovery accuracy of nutcrackers and pinyon jays when each species was given 15 and 90 holes open for caching. Overall, performance was better after the birds had selected cache sites from the 90-hole array. This effect was relatively small for nutcrackers $(12 \%)$ but was quite large for pinyon jays $(33 \%)$. This difference is undoubtedly due to the tendency of pinyon jays to place their caches very close together during the 90-hole condi- 
tion. Then, during recovery, the pinyon jays could simply return to the area where caches where clustered. Pinyon jays may remember the locations of their preferred areas in which they have clumped their caches rather than remembering individual cache sites.

We have performed several other analyses relevant to the question of site preferences. For example, several analyses which divided cache sites into preferred and nonpreferred groups on the basis of visitation during habituation sessions and order of use found no effects (Kamil \& Balda, 1985). When different nutcrackers are given the same set of holes as potential cache sites, they show only a slight tendency to avoid certain holes (Kamil \& Balda, 1990). In sum, although site preferences exist, they do not appear to have a large effect on cache recovery accuracy in nutcrackers.

\section{B. Order Effects}

As a nutcracker makes caches, it encounters the cache sites sequentially, in a particular order. We have regularly examined the data from our experiments to determine whether or not there is a consistent relationship between the order of cache creation and any aspect of cache recovery.

In several cases, we have calculated Spearman rank-order correlations between the order of caching and the order of recovery. For each bird, each cache is assigned two numbers, one reflecting its rank in the cache order and the other its rank in the recovery order. The resulting correlation coefficients show a slight overall tendency toward being positive. For example, in one experiment (Kamil \& Balda, 1990), Spearman rankorder correlations were calculated for 10 birds. The average correlation was +.01 . Three of the individual coefficients were statistically significant (at the $\alpha=.05$ level); one was significantly negative, two positive.

This failure to find a correspondence between caching and recovery orders rules out one simple interpretation of cache recovery. It is clear that the birds do not retrace the path they used during caching sessions while recovering their caches. If they were duplicating the same movement pattern, then the overall correlations would be strongly positive. (Of course, it could be argued that they retrace portions of the caching pattern during recovery. But there are no signs of regular strings of successive recoveries mirroring portions of the caching sequence either.)

Despite the absence of consistent correlations between caching order and recovery order, primacy and/or recency effects could be present. For example, if a nutcracker initially recovers a few of his early caches and a few of his late caches, this would be obscured by an overall correlation analysis. Therefore, we have conducted analyses in which we have di- 
vided caches into early, middle, and late groups based on order of creation and calculated mean ranks of recovery for each group. We have never found any differences even approaching significance. In summary, there is no strong relationship between the order in which seeds are cached and the order in which the seeds are recovered during our experiments.

\section{Decline in Accuracy}

During virtually all of our experiments, the accuracy of cache recovery declines as recovery proceeds. This decline is much more rapid than the decline in the levels of performance that would be expected by chance (as caches are removed from the room). What could account for this decline in accuracy? One possibility is that the birds remember some sites better than others and recover the better-remembered sites first. If this were true, then forcing the birds to recover their caches in a random order should eliminate the decline in accuracy.

In order to test this prediction, Kamil and Balda (1990) allowed birds to cache throughout the experimental room, so that approximately equal numbers of caches were placed in each quadrant. During the control condition, recovery proceeded as usual, with all holes in the room available during each of the four recovery sessions. During the experimental condition, we controlled recovery order across sessions. During each of the four recovery sessions only one quadrant of the room was available; the holes in the other three quadrants were capped with wooden plugs. Each bird recovered from each of the four quadrants in a different random order across the four recovery sessions.

One factor complicated the analysis. The levels of performance expected by chance declined from session to session only during the control condition because the proportion of holes containing seeds declined as recovery proceeded. Despite this complication, the results clearly supported the hypothesis. Even when recovery accuracy was adjusted to take this difference into account, performance during the control condition declined markedly over sessions, but recovery accuracy was virtually constant during the experimental recovery sessions (Figure 1). Perhaps the clearest aspect of the results is that during the very first recovery session, when chance levels were identical for the two conditions, recovery accuracy was significantly higher when all holes were available than when only one quadrant was available. It seems clear that the nutcrackers were first recovering the caches that they remembered best.

It is particularly interesting to consider this result in conjunction with the evidence reviewed above that there is no relationship between caching 


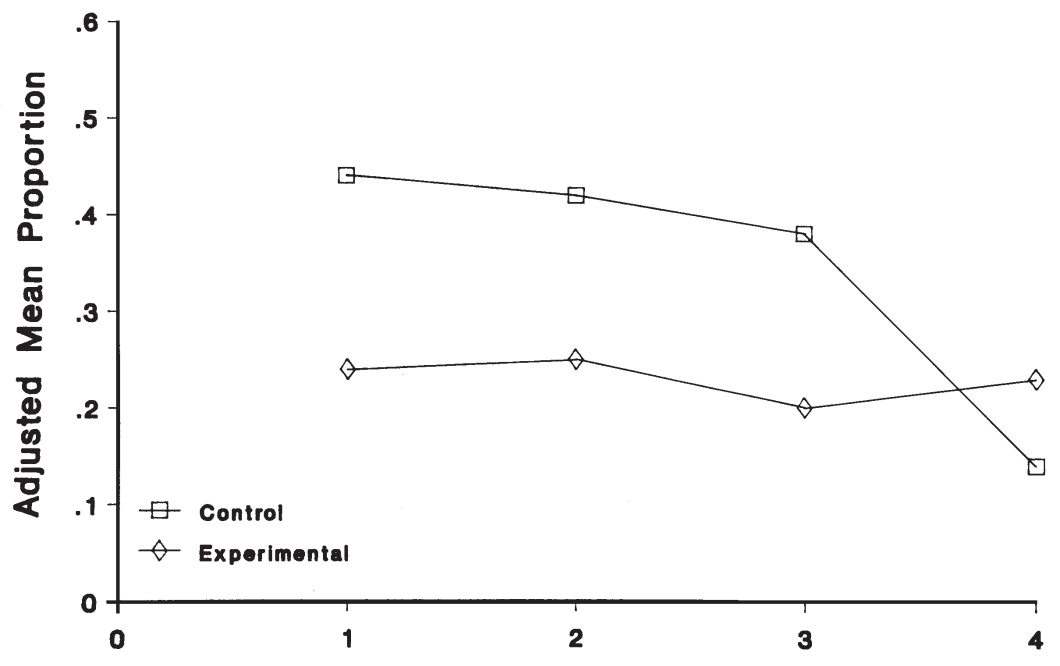

\section{Recovery Session}

Figure 1. Performance during cache recovery when all holes were available during each recovery session (control) or when only one quadrant of the room was open during each recovery session (experimental). The modified accuracy score takes into account differences in the levels of performance expected by chance by using the ratio (accuracy - chance)/ $(1.00$ - chance).

order and recovery order. It is clear that some sites are remembered better than others and that these sites are recovered first. But caching order has no discernible effect on recovery order. This clearly implies that caching order is unrelated to how well sites are remembered. However, recovery order appears to be a good index of memorability. The best-remembered sites are probably those that are recovered first. We took advantage of this aspect of the cache recovery behavior of nutcrackers to further investigate the causes of differential memory for different cache sites.

The logic of the experiment was simple. Birds were forced to use the same locations as cache sites during two successive cache-recovery cycles. Suppose some sites are better remembered than others because of a physical attribute, such as proximity to a conspicuous landmark. Then if the same sites have caches placed in them twice, they should be recovered in the same order during each cycle.

During the first stage of this experiment, nutcrackers were allowed to make 15-18 caches in 45 holes. After recovering these caches, they were 
given another caching session with only the previously used holes available for caching. The birds cached in these holes and then they recovered again. During both recovery sessions, the same set of 90 holes was open.

Performance declined significantly as recovery proceeded during both stages, indicating that some sites were, in fact, remembered better than others during each stage. But there was no consistent relationship between the order of recovery during Stage 1 and the order of recovery during Stage 2. Clearly, if the decline in performance is a measure of differential memory, the different recovery orders in response to the same set of cache sites shows that the best-remembered sites were different during the two stages. This presents strong, albeit negative, evidence against any inherent physical characteristic of the sites being responsible for differential memory.

The questions of differential memory for different cache sites and of recovery order need further analysis. If the source of differential memory is not inherent physical differences between sites, perhaps it can be found in different behaviors at different sites during caching. For example, the best-remembered sites may be those at which the caching bird spends the most time or makes the most probes. Detailed analysis of caching behaviors may resolve this issue.

\section{What Is the Duration of Cache Site Memory?}

The natural history of the nutcracker suggests that cache site memory must have a duration of at least 9-10 months. Nutcrackers have been observed accurately recovering cached seeds in the field in the spring to early summer, at least 9 months after the caches must have been made the previous fall (Vander Wall \& Hutchins, 1983). We have begun to explore the duration of cache site memory in the laboratory.

In a pilot study, three nutcrackers were allowed to cache in the fall. Then they were allowed to recover some of their caches 1 week, 3 months, and 6 months later. Performance did decline somewhat from 1 week to 6 months, but some decline is to be expected as recovery proceeds (Kamil \& Balda, 1985). The important consideration is that the performance of all three birds was significantly above chance after 6 months.

We are currently conducting a large scale, long-term, between-group experiment. Four groups of six to seven birds each were allowed to cache in the fall. One group was tested after 7 days, another after 3 months, another after 6 months, and another will be tested after 10 months. So far, there are no significant differences, or even a hint of consistent differences, among the 1-week, 3-month, and 6-month groups. Clearly, the limits of nutcracker memory for cache location are greater than 6 months. 


\section{E. The Effects of Performance Factors}

During cache recovery tasks, nutcrackers perform consistently above chance during laboratory experiments, at levels comparable to those observed in field situations. Accuracy levels of .25 to .70 are not uncommon in field and laboratory. However, it is not clear if the errors that are made under laboratory conditions reflect limits of the spatial abilities of these birds or if some other, performance factors are responsible. Several incidents suggest that some probes we record as errors are not due to failures of memory.

For example, on some occasions we have observed a bird that was previously recovering seeds accurately suddenly begin to frantically search through many adjacent holes. This behavior is characterized by a very rapid probing of holes located next to each other. After some time this behavior ceased and the bird again probed more deliberately with high accuracy. These probes are recorded as errors, but they may represent something other than memory failure. One possibility is that the bird is looking for seeds cached by other birds. This was suggested to us by an episode with one nutcracker during habituation. Through experimenter error, a seed was accidentally left in a hole where it had been placed by another bird during an earlier session. The bird found this seed, perhaps because it was only partially buried. It then proceeded to dig up all empty holes, going rapidly from one to the next. In fact, this bird was ruined as an experimental subject because it would always engage in this behavior thereafter.

On other occasions we have observed birds make numerous errors at the end of a recovery session and not recover their last one or two caches in the room. Upon return to the room at some later time the birds recover these last caches immediately, with no errors. In two cases, we have seen birds recover their last cache and then stop all digging behavior, as if they "knew" there were no more seeds in the room. Taken together these observations offer at least anecdotal evidence that nutcrackers may know more about the location of their caches than their error rates indicate. We have examined the effects of several performance factors on error rates.

Errors may increase near the end of recovery sessions due to satiation. Birds are tested after being deprived of food for $24 \mathrm{hr}$ and then eat the seeds they find. If accuracy is related to hunger levels, then error rates might increase as hunger declines across the session. We tested this possibility (Kamil \& Balda, 1985) by testing four nutcrackers under two conditions (with order of testing counterbalanced). Birds were allowed to make up to 12 caches in 27 randomly selected holes. After a 7-day retention intervals birds were allowed to recover their caches. In one condition birds were pre-fed before entering the room for the recovery session, 
whereas in the other condition birds were deprived of food for $24 \mathrm{hr}$ before testing (our usual procedure). Nutcrackers were consistently above chance under both conditions of the experiment, and there was no significant difference in performance between pre-fed and satiated birds. These results suggest that hunger level is not responsible for the drop-off in performance toward the end of test sessions.

In nature, nutcrackers cache in a variety of substrates, ranging from coarse gravel to fine clays. We have used fine sand as the caching substrate, which is probably easier to dig in than natural substrates. Thus, errors may be relatively inexpensive in our experiments and this may account for some of them. We tested six nutcrackers under two conditions. They cached and recovered from cups that contained fine sand in one condition and from cups filled with a mixture of fine sand and pebbles in the other condition. The pebbles were similar in size to the pine seeds used in the experiment. The birds cached readily during both conditions. The sand/pebble mixture appeared to be more difficult because the pebbles impeded the forceful thrust of the bill normally associated with the creation of a cache. During recovery birds probed more and spent more time at sand/pebble sites. Under the latter condition caches were found with significantly fewer probes than when the cups contained only sand. These results show that recovery accuracy is influenced by the cost of digging and that error rates are not a function of memory alone.

\section{Species Differences in Cache Site Memory}

Clark's nutcrackers are not the only birds who cope with fluctuation in food availability by storing food for later use in many widely dispersed sites. This adaptation is fairly common among parids (the chickadees and tits; Sherry, 1984) and ubiquitous among corvids (the jays, crows, and nutcrackers; Balda \& Kamil, 1989; Goodwin, 1976). Among the corvids, there is considerable variation in the extent to which different species are dependent upon stored food. Three species of the American Southwest, the Clark's nutcracker (Nucifraga columbiana), pinyon jay (Gymnorhinus cyanocephalus), and scrub jay (Aphelocoma coerulescens) differ in the extent to which they depend on stored food. They also differ in the extent of their morphological specializations for the harvesting, transport, caching, and recovery of seeds (Vander Wall \& Balda, 1981).

Clark's nutcrackers live year-round at high elevations where other foods are not available during winter and spring. They cache between 22,000 and 33,000 seeds in some autumns, and their diet consists of close to 
$100 \%$ stored pine seeds during the unproductive winter months. As noted earlier, nutcrackers have a strong sharp bill, that they use to open tightly closed green pine cones, and a unique sublingual pouch in which they can transport up to 95 whole seeds. In alpine areas these birds breed in March and April and their nestlings can survive on a diet of pine seeds.

Pinyon jays, a highly social species, live at lower elevations, cache thousands of seeds, and eat between 70 and $90 \%$ stored pine seeds in winter. These jays can carry up to 45 pine seeds in an expandable esophagus, have a sharp bill (also used to open green pine cones), breed very early in spring, and feed their nestlings some pine seeds.

Scrub jays live year-round in the mild, pinyon-juniper woodland and eat a wide variety of foods. They probably cache no more than 6,000 pine seeds in fall, can transport no more than 4 seeds in mouth and bill, and have a very generalized, blunt bill. These birds breed in early summer.

Thus, these three species vary systematically in the elevations at which they live, the number of seeds they cache, and their morphological specializations for harvesting and storing seeds. Based on these features, the species can be regarded as showing a specialization gradient from nutcracker to scrub jay, with the pinyon jay being intermediate. Are there species differences in the accuracy of cache recovery that reflect this gradient? If so, we expect nutcrackers to perform best, pinyon jays somewhat worse, and scrub jays worst of all.

To answer this question, Balda and Kamil (1989) tested seven birds of each species under two conditions, with order of testing counterbalanced. During one condition, the birds were allowed to select cache sites from 90 opened holes in the room. These holes were spaced evenly throughout the room. Each bird was placed in the room individually and allowed to make 8 caches. The bird was then removed for a 7-day retention interval. During this time we removed all signs of digging activity from the room. The bird was then allowed back in the room with all 90 holes open and seeds present in the holes used by the bird during the caching session. During the second condition, a different set of 90 holes within the caching room was used. During caching, only 15 randomly selected holes (out of the 90) were available to the bird. Again, the bird was allowed to make 8 caches. After another 7-day retention interval birds were allowed into the room to recover their caches with all 90 holes open.

This design was used because different species may employ different mechanisms to locate their seed caches. For example, when birds are given free choice of many cache sites to use, such as during condition 90, they may employ a "caching rule" or demonstrate a preference of some type for certain sets of holes. Then, during recovery sessions only the rule or preference need be remembered. Limiting the number of cache sites, 


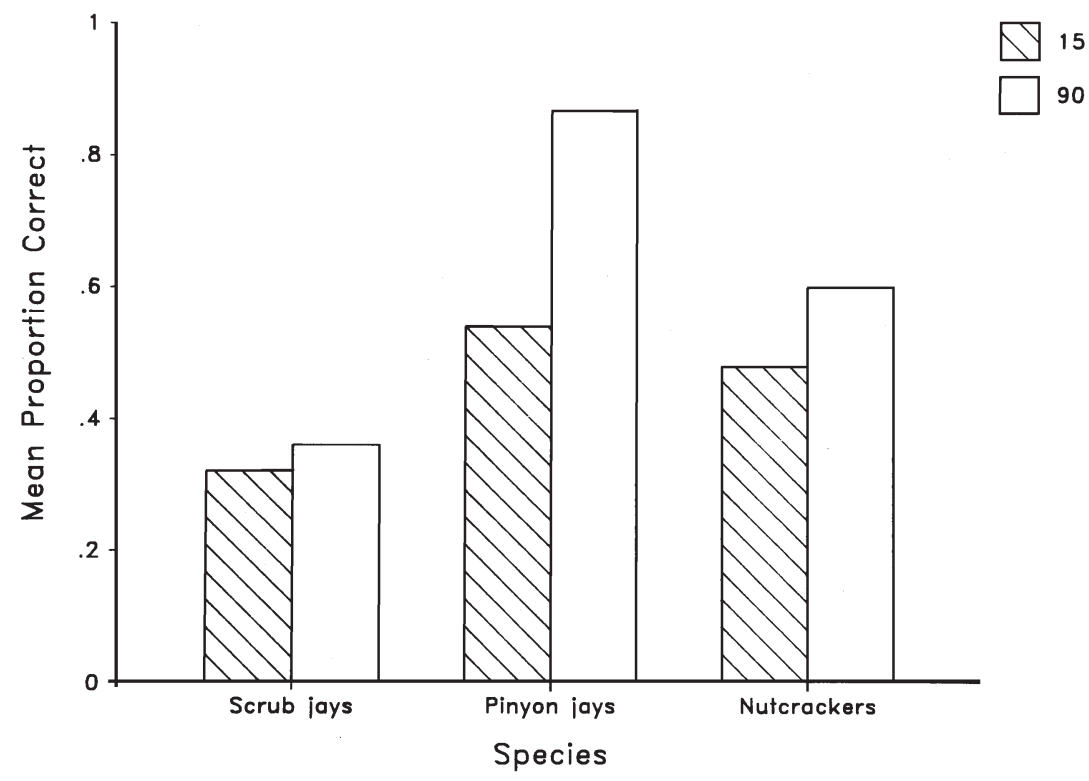

Figure 2. Mean performance of each species after 90 holes were available for caching (open bars) or after only 15 holes were available (cross-hatched bars).There were always 90 holes available during recovery sessions.

such as during condition 15, would limit these cache placement strategies. In essence, condition 15 forces the bird to place its caches in a set of holes chosen by the experimenters.

All birds readily cached and recovered seeds under both conditions. Accuracy varied as a function of both species and condition (Figure 2). Scrub jays performed significantly worse than either pinyon jays or nutcrackers, which did not differ from each other. Performance was generally better during the 90-hole condition, especially for the pinyon jays, who performed exceptionally well during condition 90 and showed a marked decline in condition 15 . The reason for this marked effect of number of holes available on cache recovery in pinyon jays was the spatial clustering of cache sites described above.

These results support our specialization hypothesis, that the accuracy of cache recovery varies as a function of the ecology and natural history of the species being tested. Nutcrackers and pinyon jays, the two species most dependent on cached seeds in nature, performed significantly better than scrub jays. 


\section{Noncaching Tests of Spatial Memory}

The comparative experiment demonstrated differences between nutcrackers and scrub jays in cache-recovery accuracy. However, data from seminatural cache-recovery experiments cannot adequately test whether or not these differences are due to species differences in spatial memory. This will require testing the species under conditions that offer more control over parameters such as duration of exposure to the to-be-remembered location. This suggests comparative experiments using more traditional psychological procedures. In order to accomplish this goal, we have begun to test nutcrackers in an analog of the radial maze and with operant procedures.

\section{A. Radial-Arm Maze}

During a forced-choice radial-arm maze procedure (e.g., Beatty \& Shavalia, 1980), each trial is divided into two parts. During the preretention, information stage, the rat chooses a subset of the arms of the maze. Then, following the retention interval, the animal is given free choice among all of the arms of the maze and rewarded for visiting those arms not earlier visited. This procedure was adapted for nutcrackers by using eight of the holes in our cache-recovery room (Balda \& Kamil, 1988). One set of eight holes, arranged in a rough circle, was used throughout the experiment. During each trial, each nutcracker was allowed in the room twice. During the preretention phase only four of the holes were open. These holes were randomly chosen on each trial, and each contained a single pine seed buried below the surface of the sand by the experimenter. After the bird dug up and ate these four seeds, the room lights were flashed as a signal to leave the room. During the retention interval, the bird remained in its cage while the experimenter entered the room, uncapped the four capped holes, buried one seed in each of these previously capped holes, and cleaned up any signs of previous activity. When the retention interval was over, the bird reentered the room for the test phase. During the test phase all eight holes were open, but only holes that had not been visited earlier contained seeds.

During preliminary training, the retention interval was held at $5 \mathrm{~min}$. At first, the birds showed a pattern of visiting all of the available holes in a circular path. However, once we introduced a large set of rocks and logs that made hopping from one hole to the next more difficult, performance improved rapidly, reaching asymptotic levels of over $80 \%$.

After this initial training was complete, we tested the birds with seven different retention intervals ranging between $5 \mathrm{~min}$ and $24 \mathrm{hr}$ (Figure 3). 


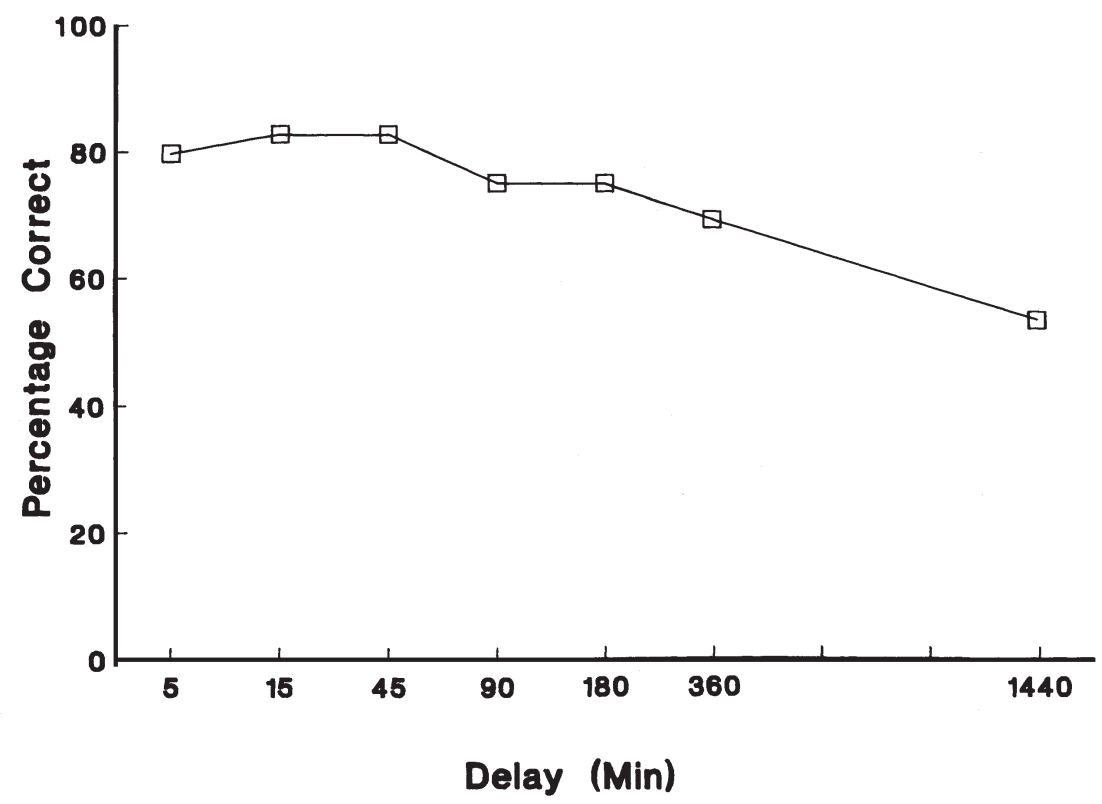

Figure 3. Mean percentage correct choices during radial-maze analog testing after different duration retention intervals.

There was no significant decline in performance through $6 \mathrm{hr}$, but performance after a $24-\mathrm{hr}$ retention interval was close to chance. These results are markedly different from those obtained in similar studies of pigeons and from the cache-recovery results described above.

In comparison to the results of cache-recovery experiments, the performance observed in the radial-maze analog experiment is unimpressive. For example, high accuracy levels after retention intervals of 10-15 days, with 25-30 cache sites to be remembered, have routinely been observed in nutcrackers (Kamil \& Balda, 1985). On the surface, this comparison suggests that the nutcrackers may use different memory systems during radial-maze and cache-recovery tests. However, several procedural differences between the tasks may account for the differences.

The most important of these appears to be proactive interference. During radial-maze tests, the set of locations to be remembered changes daily, on each trial. During a cache-recovery experiment the set of locations to be remembered does not change within a single test. Another potentially important factor is the difference in required response strategies. During caching tests of memory, the bird first places a seed in a 
location, then is required to return to that location. But during radialmaze testing, the bird first removes a seed, then is required to avoid that location. These response differences could also affect performance. We are currently testing the effects of these variables upon cache-recovery and radial-maze analog performances to try to determine if the methodological differences can account for the apparent differences in memory duration.

While the radial-maze results may be unimpressive compared to nutcracker cache-recovery performance, they are quite impressive compared to the performance of pigeons during tests in a radial maze (Roberts \& Van Veldhuizen, 1985) as well as open-field tests in radial-maze analogs (Spetch \& Edwards, 1986; Spetch \& Honig, 1988). For example, Spetch and Honig (1988) obtained the best performance from pigeons in radialmaze-type settings. In their experiment there was very substantial forgetting within $2 \mathrm{hr}$. The nutcrackers in our radial-maze analog, in contrast, showed no significant forgetting after $6 \mathrm{hr}$. These differences suggest large species differences among birds in spatial memory ability. Experiments simultaneously testing several species will be required.

In our view, the experiment that would be most useful would be one that compared closely related species that differed in their dependence on cached food. This would directly test the possibility raised by the results of our comparative cache-recovery experiment-that spatial memory varies as a function of this ecological factor. We hope to carry out such an experiment in the near future.

\section{B. Operant Spatial Nonmatching to Sample}

Although we have not yet carried out the needed comparative radialmaze study, we have examined the performance of nutcrackers, scrub jays, and pigeons in an operant test of spatial memory. Olson (1989) developed a spatial nonmatching-to-sample procedure during which there were two stages to each trial-a preretention stage and a postretention choice stage. The experiments were conducted in a 1.35-m-long operant chamber, with two pecking keys on the front wall and a single key and a food cup on the rear wall. During the first stage, one of the keys on the front wall, randomly chosen on each trial, was lit. The subject was required to peck this key five times. Then the key was darkened and the retention interval began. During the retention interval, the bird pecked the illuminated key on the back wall. The retention interval ended after the first response following the scheduled retention interval (see below for an explanation of how retention interval was manipulated). At the end of the retention interval, the back key was darkened and both front keys 


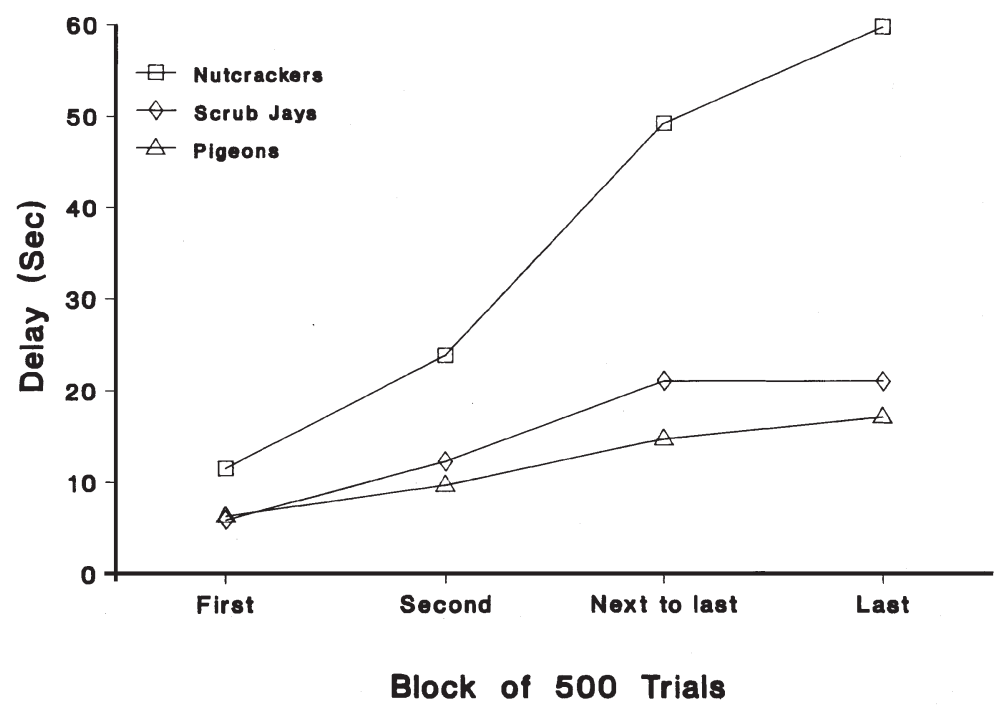

Figure 4. The mean titrated delay values during blocks of 500 trials of operant spatial nonmatching to sample for each of three species. Because the delay could increase only as long as performance was better than $75 \%$ correct, higher values indicate better performance.

lit up. If the bird pecked at the key that was illuminated during the preretention stage of the trial, the trial ended without reinforcement. If the bird chose the front key that was not illuminated during the preretention stage, the trial ended with a reinforcement (a piece of pine seed) delivered in the food cup on the rear wall.

A titration procedure was used to continuously adjust the duration of the retention interval. Whenever a correct choice was made, the interval increased by . 1 sec on the next trial; after an incorrect choice, the interval decreased by $.3 \mathrm{sec}$. Thus, the duration of the retention interval kept slowly increasing as long as performance was above $75 \%$ correct. The advantage of the titration procedure is that it concentrates data collection at the limits of the abilities of the subjects. In addition, because it is open ended, it is particularly appropriate when the limits of memory for the species being tested are unknown.

Olson has tested three species: nutcrackers, scrub jays, and pigeons. The performance of the nutcrackers was spectacular. They performed well with retention intervals of 70-80 sec and showed no signs of having reached asymptote at the end of the experiment. The pigeons performed very poorly, never consistently achieving retention intervals of $10 \mathrm{sec}$. The scrub jays performed at levels intermediate to nutcrackers and pigeons, but more like pigeons than nutcrackers (Figure 4). 
Olson (1989) has replicated these effects with nutcrackers and scrub jays, using fixed retention intervals from 0 to $30 \mathrm{sec}$ and varying the memory load. There were four pecking keys on the front wall, and the number of samples presented varied from one to three. During the test phase, there were always two keys illuminated, one of which had been illuminated during the preretention phase. The correct response was to choose the test stimulus that had not been illuminated on that trial. Again, the nutcrackers consistently outperformed the scrub jays.

The results of these two operant experiments demonstrate that the species differences observed during cache recovery also are found during operant tests of spatial memory. They offer strong support for the hypothesis that the differences in cache-recovery accuracy are caused by differences in spatial memory ability. More generally, they suggest a direct relationship between one parameter of natural history, dependence on cached food, and spatial memory.

\section{Implications and Future Directions}

Although this research project started from natural history and ecology, the results have many implications of general interest to psychologists. In this section, we discuss three of these implications, with an emphasis on questions that remain for further research.

\section{A. Implications for Comparative Research}

Although the psychological literature on animal learning and memory is huge, encompassing thousands of publications, comparative research makes up a relatively small part of this literature. There are many reasons for this relative disinterest in comparative work (for discussion see Beach, 1950; Bitterman, 1960; Kamil, 1988; Staddon, 1989). One of the major reasons, however, has been the absence of a consistent straightforward methodology to circumvent the problems presented by the learning-performance distinction.

The basic problem is simple: The major comparative question of interest to psychologists is that of species differences in cognitive abilities. But species differences in any particular situation may be due to factors that affect performance, "contextual variables," rather than species differences (Bitterman, 1960, 1965; Macphail, 1982, 1985). Control by systematic variation is one way to deal with this problem (e.g., Bitterman, 1960; Macphail, 1982). According to this argument, performance factors such as stimulus and response requirements, motivation, and reward should be systematically varied. If a species difference is reliably observed under 
all variations, it can be concluded that the difference is due to a difference in ability (or process).

The problem with this approach is that it treats the hypothesis of species difference as a null hypothesis which can be disproved only by proving another null hypothesis: that the species difference will appear under all circumstances. This leaves no way, within this framework, to conclusively demonstrate species differences in learning ability. It is always possible that a species difference would disappear under some as yet unspecified and untested set of circumstances (see Kamil, 1988, for a detailed discussion of this issue). In order for comparative research on cognitive abilities to move forward, a way must be found around the very real problems of the learning-performance distinction.

The key to avoiding these problems is to have a priori predictions of species differences in cognitive abilities, predictions that can be subjected to multiple independent tests. An approach based on natural history and ecology can provide such predictions based on analyses of the adaptations of species to their natural habitat. Such analyses can provide specific, directional hypotheses about species differences in cognitive processes.

For example, consider the hypothesis that spatial memory abilities will be greater in animals that are most dependent upon scattered cached food stores that are relocated through the use of spatial memory. This hypothesis receives strong support from the differences between nutcrackers and scrub jays, especially in the operant nonmatching experiments. However, a skeptic could always claim that this difference was due to some contextual variable that favored the nutcrackers, no matter how many times it was replicated using control by systematic variation. For example, it could be argued that nutcrackers simply adapt to laboratory environments better than scrub jays.

However, the hypothesis can be tested with other groups of animals. For example, some parids, such as marsh tits and black-capped chickadees, cache seeds while other species of the same genus, such as great tits, do not. Recently, Krebs, Healy, and Shettleworth (in press) compared coal tits and great tits on a "window-shopping" task which required the birds to remember where they had earlier seen seeds. The coal tits, who regularly cache seeds in nature, performed better than the great tits, a noncaching species. If repeated tests of the hypothesis with different groups of animals produce data that support the hypothesis, then the contextualvariable argument becomes untenable. Although performance factors might happen to produce the predicted differences in any one case, they are unlikely to do so in multiple cases.

It should be noted that this strategy uses analysis of the adaptations of animals to the problems encountered in their natural habitat in the selec- 
tion of both species and paradigms for experiments. The strategy can be used quite generally. For example, Humphrey (1976) has suggested that social functions have been extremely important in the evolution of intellect in animals. Thus, the gauging of social relations among members of the group may be learned, and crucial to biological success (e.g., Bachmann \& Kummer, 1980; Goodall, 1986). This hypothesis could be tested by comparative studies of closely related species which vary in their social organization. Most importantly, these tests could be carried out independently in different groups of animals, such as birds and primates.

\section{B. The Generality of Nutcracker Spatial Memory}

Why do Clark's nutcrackers perform better than scrub jays during operant spatial nonmatching? This question can be answered at many levels: neural, behavioral, and evolutionary. At the neural level, we do not yet know whether there are systematic differences between nutcrackers and scrub jays. However, research comparing caching and noncaching species (Krebs, Sherry, Healy, Perry, \& Vaccarino, in press; Sherry \& Vaccarino, in press) has found that there are systematic differences in the relative size of the hippocampus. Caching species have larger hippocampi. At the behavioral level, the best hypothesis is that species differences in spatial memory are responsible, although further tests are needed. And at the evolutionary level, the differences in dependence on cached food leading to neural differences, which in turn produce differences in spatial memory, is the most viable hypothesis. One of the advantages of this approach is that it offers a method of bridging the gap between different levels of explanation of behavioral differences between species.

Each of these tentative explanations has one thing in common: Each implies that the underlying mechanism responsible for accurate cache recovery is the same as that responsible for performance during the operant task. If this is true, it provides a clear example of natural history influencing behavior in highly artificial and abstract psychological test environments.

The traditional approach to the psychological study of animal learning tended to assume that the behaviors observed during tests in artificial environments (such as operant chambers) were not directly related to the natural behaviors of the animal being studied in any important way (e.g., Skinner, 1959). Biological constraints on learning have challenged that assumption. Phenomena such as species-specific defensive reactions (Bolles, 1970) and autoshaping (Jenkins \& Moore, 1973) have demonstrated that there can be a rather direct connection between the natural repertoire of the animal and what it does during a learning experiment. 
The logic connecting the performance of nutcrackers during operant spatial tests with their natural history is somewhat different. Spatial relationships are important to most mobile animals (if not all), and spatial memory is widespread. However, in the case of organisms dependent on memory to locate scattered food, memory is particularly important. Therefore, in such cases, natural selection may have acted to improve the spatial memory systems of these animals. Once spatial memory has improved, this improvement will be reflected in any test of spatial memory. This argument suggests that a cognitive ability can be the trait on which selection operates. This, in turn, implies that the research strategies that biologists have used to study the species differences in physical traits can also be adapted to the study of the evolution of cognitive traits. And, of course, cognitive traits are basically physical traits at the level of the structure of the nervous system.

\section{Implications for Memory Systems}

Sherry and Schacter (1987) have offered a persuasive argument for the evolution of separate memory systems under certain circumstances. If there are two separate natural settings which demand the use of memory, and if the characteristics of the needed memory are functionally incompatible, then separate, specialized memory systems should evolve. This may explain the existence of "habit" or "procedural" memory versus "declarative" or "episodic" memory.

The superior performance of nutcrackers during different types of tasks requiring spatial memory, cache recovery, and operant nonmatching suggests that the spatial memory system that nutcrackers use for cache recovery is not limited to that situation. That is, it appears that the same memory system may be used, although much further work will be needed to be sure of this. However, the hypothesized generality of the nutcracker spatial memory should not be taken as evidence against Sherry and Schacter's (1987) suggestion of separate memory systems in the face of functional incompatibility. The major requirements for a spatial memory system to keep track of cache site location in Clark's nutcrackers appears to be that the system be of large capacity and long duration. These characteristics are not functionally incompatible with other types of functions that spatial memory may serve.

\section{Conclusions}

Our studies of cache recovery and spatial memory began with an issue raised by the natural history and ecology of the nutcracker. We hope 
that this review of our work has convinced the reader that natural history and ecology can provide a good starting point for research programs that produce data that bear directly on central issues of psychology: the cognitive abilities of animals, the evolution of learning and memory, and the structure of memory, for example. We further hope that readers are encouraged to utilize this strategy in their own research. We are convinced that systematic and widespread use of this strategy will lead to the discovery of many other dramatic and important examples of cognitive processes in animals.

\section{Acknowledgments}

The research reported in this article was supported by NSF grants BNS 82-08286 and BNS 85-19010 and NIH grant MH-44200.

\section{References}

Bachmann, C., \& Kummer, H. (1980). Male assessment of female choice in Hamadryas baboons. Behavioral Ecology and Sociobiology, 6, 315-321.

Balda, R. P. (1980). Are seed-caching systems co-evolved? In R. Nohring (Ed.), Acta XVI Congressus Internationalis Ornithologici (pp. 1185-1191). Berlin: Deutsche Ornitologen-Gesellschaft.

Balda, R. P., Bunch, K. G., Kamil, A. C., Sherry, D. F., \& Tomback, D. F. (1987). Cache site memory in birds. In A. C. Kamil, J. R. Krebs, \& H. R. Pulliam (Eds.), Foraging behavior (pp. 645-666), New York: Plenum.

Balda, R. P., \& Kamil, A. C. (1988). The spatial memory of Clark's nutcrackers (Nucifraga columbiana) in an analog of the radial-arm maze. Animal Learning and Behavior, 16, 116-122.

Balda, R. P., \& Kamil, A. C. (1989). A comparative study of cache recovery by three corvid species. Animal Behaviour, 38, 486-495.

Beach, F. A. (1950). The snark was a boojum. American Psychologist, 5, 115-124.

Beatty, W. W., \& Shavalia, D. A. (1980). Spatial memory in rats: Time course of working memory and effect of anesthetics. Behavioral and Neural Biology, 28, 454-462.

Bitterman, M. E. (1960). Toward a comparative psychology of learning. American Psychologist, 15, 704-712.

Bitterman, M. E. (1965). Phyletic differences in learning. American Psychologist, 20, 396-410.

Bock, W. J., Balda, R. P., \& Vander Wall, S. B. (1973). Morphology of the sublingual pouch and tongue musculature in Clark's nutcracker. Auk, 90, 491-519.

Bolles, R. C. (1970). Species-specific defense reactions and avoidance learning. Psychological Review, 77, 32-48.

Cheney, D., Seyfarth, R., \& Smuts, B. (1986). Social relationships and social cognition in nonhuman primates. Science, 234, 1361-1366. 
Conrads, K., \& Balda, R. P. (1979). Uberwinterungschancen Siberischer Tannenhaher (Nucifraga caryocatactes macrorhynchos) im Invasionsgebeit. Bericht der Naturwissenschaftlischen Veirens, Bielefeld, 24, 115-137.

Garcia, J., \& Koelling, R. A. (1966). Relation of cue to consequence in avoidance learning. Psychonomic Science, 4, 123-124.

Goodall, J. (1986). The chimpanzees of Gombe: Patterns of behavior. Cambridge, MA: Harvard University Press.

Goodwin, D. (1976). Crows of the world. Ithaca, NY: Cornell University Press.

Humphrey, N. K. (1976). The social function of intellect. In P. P. G. Bateson \& R. A. Hinde (Eds.), Growing points in ethology (pp. 303-318). Cambridge: Cambridge University Press.

Jenkins, H. M., \& Moore, B. R. (1973). The form of the autoshaped response with food and water reinforcers. Journal of the Experimental Analysis of Behavior, 20, 163-181.

Kamil, A. C. (1988). A synthetic approach to the study of animal intelligence. In D. W. Leger (Ed.), Comparative perspectives in modern psychology: Nebraska symposium on motivation (Vol. 35, pp. 257-308). Lincoln: University of Nebraska Press.

Kamil, A. C., \& Balda, R. P. (1985). Cache recovery and spatial memory in Clark's nut crackers (Nucifraga columbiana). Journal of Experimental Psychology: Animal Behavior Processes, 11, 95-111.

Kamil, A. C., \& Balda, R. P. (1990). Differential memory for cache sites in Clark's nutcrackers. Journal of Experimental Psychology: Animal Behavior Processes, 16, 162-168.

Kamil, A. C., \& Mauldin, J. E. (1987). A comparative-ecological approach to the study of learning. In: R. C. Bolles \& M. D. Beecher (Eds.), Evolution and learning (pp. 117-133). Hillsdale, NJ: Erlbaum.

Krebs, J. R., Healy, S. D., \& Shettleworth, S. J. (in press). Spatial memory of Paridae: comparison of a storing and a non-storing species. Animal Behaviour.

Krebs, J. R., Sherry, D. F., Healy, S. D., Perry, V. H., \& Vaccarino, A. L. (1989). Hippocampal specialization of food-storing birds. Proceedings of the National Academy of Sciences USA, 86, 1388-1392.

Macphail, E. M. (1982). Brain and intelligence in vertebrates. London: Oxford University Press (Clarendon).

Macphail, E. M. (1985). Vertebrate intelligence: The null hypothesis. In L. Weiskrantz (Ed.), Animal intelligence (pp. 37-50). London: Oxford University Press (Clarendon).

Mewaldt, R. (1956). Nesting behavior of the Clark's nutcracker. Condor, 58, 3-23.

Olson, D. (1989). Comparative spatial memory in birds. Unpublished doctoral dissertation, University of Massachusetts, Amherst.

Roberts, W. A., \& Van Veldhuizen, N. (1985). Spatial memory in pigeons on the radial maze. Journal of Experimental Psychology: Animal Behavior Processes, 11, $241-260$.

Sherry, D. F. (1984). What food-storing birds remember. Canadian Journal of Psychology, 38,304-321.

Sherry, D. P., \& Schacter, D. L. (1987). The evolution of multiple memory systems. Psychological Review, 94, 439-454. 
Sherry, D. F., \& Vaccarino, A. L. (1989). The hippocampus and memory for food caches in Black-capped chickadees. Behavioral Neuroscience, 2, 308-318.

Shettleworth, S. J. (1984). Learning and behavioral ecology. In J. R. Krebs \& N. B. Davies (Eds.), Behavioral ecology (2nd ed., pp. 170-196). Sunderland, MA: Sinauer Associates.

Skinner, B. F. (1959). A case history in scientific method. In S. Koch (Ed.), Psychology: The study of a science (pp. 359-379). New York: McGraw-Hill.

Spetch, M. L., \& Edwards, C. A. (1986). Spatial memory in pigeons (Columba livia) in an "open-field" feeding environment. Journal of Comparative Psychology, 100, 279-284.

Spetch, M. L., \& Honig, W. K. (1988). Characteristics of pigeons' spatial working memory in an open-field task. Animal Learning and Behavior, 16, 123-131.

Staddon, J. R. (1989). Animal psychology: The tyranny of anthropocentrism. In P. P. G. Bateson \& P. H. Klopfer (Eds.), Perspectives in ethology: Whither ethology (pp. 123-136). New York: Plenum.

Stephens, D. W., \& Krebs, J. R. (1986). Foraging theory. Princeton, NJ: Princeton University Press.

Tomback, D. (1980). How nutcrackers find their seed stores. Condor, 82, 10-19.

Turcek, F., \& Kelso, L. (1968). Ecological aspects of food transportation and storage in the Corvidae. Communications in Behavioral Biology, Part A, 1, 277-297.

Vander Wall, S. B. (1982). An experimental analysis of cache recovery in Clark's nutcracker. Animal Behaviour, 30, 84-94.

Vander Wall, S. B., \& Balda, R. P. (1977). Coadaptations of the Clark's nutcracker and the pinon pine for efficient seed harvest and dispersal. Ecological Monographs, 47, 89-111.

Vander Wall, S. B., \& Balda, R. P. (1981). Ecology and evolution of food-storage behavior in conifer-seed-caching corvids. Zeitschrift fur Tierpsychologie, 6, 217-242.

Vander Wall, S. B., \& Hutchins, H. E. (1983). Dependence of Clark's nutcracker (Nucifraga columbiana) on conifer seeds during the postfledgling period. Canadian Field Naturalist, 97, 208-214.

Vander Wall, S. B., \& Smith, K. G. (1987). Cache-protecting behavior of food-storing animals. In A. C. Kamil, J. R. Krebs, \& H. R. Pulliam (Eds.), Foraging behavior (pp. 611-644). New York: Plenum. 